\title{
LEVANTAMENTO DA FAUNA ACAROLOGICA ECTOPARASITA DE SERPENTES NÃO VENENOSAS DO ESTADO DE SÃO PAULO
}

NELIDA M. LIZASO

\section{ABSTRACT}

The ectoparasitic mite fauna of non-poisonous snakes from the Estado de São Paulo was surveyed during the period of March, 1976 to September, 1979. Considerations are made about the systematics and ecology of the genera studied. A total of 1969 snakes belonging to 30 genera was examined. This study also includes data on multiple parasitism, diversity of the mite fauna, abundance of each genera of mite, for the 4 families and 7 genera of mites.

\section{INTRODUÇĀO}

O conhecimento da fauna acarológica ectoparasita de serpentes não venenosas da Região Neotropical aumentou consideravelmente nos últimos anos pela coleta sistemática feita em exemplares vivos que chegam semanalmente ao Instituto Butantan, procedentes das mais diversas regiões do Brasil (Lizaso, 1983).

Este tipo de coleta permitiu também estudo ecológico, pois as serpentes são examinadas antes de serem colocadas em viveiros ou serpentários, o que impede infestações posteriores que dificultariam a precisão dos dados.

\section{MATERIAL E METODO}

O material examinado provem das seguintes localidades do Estado de São Paulo: Arujá, Álvares Machado, Agudos, Assis, Araraquara, Araçoiaba da Serra, Aparecida do Norte, Araçatuba, Barueri, Barretos, Boa Esperança do Sul, Birigui, Bebedouro, Buri, Biritiba Mirim, Cotia, Caieiras, Castilho, Capão Bonito, Carapicuíba, Colômbia, Campos do Jordão, Catanduva, Cajuru, Casa Branca, Dracena, Embu, Engenheiro Marcilac, Embu Guaçu, Fernandópolis, Franca, Franco da Rocha, Garça, Guaraçaí, Guararema, Guarulhos, Itapecerica da Serra, Itapé, Itanhaém, Itu, Indaiatuba, Inúbia Paulista, Itapetininga, Iacanga, Itirapina, Juquiá, Jundiaí, Jaú, Juquitiba, Jacareí, Lavínia, Louveira, Martinópolis, Mairiporã, Mirassol, Mirandópolis, Miracatu, Mogi das Cruzes, Nazaré Paulista, Nova Odessa, Oriente, Ourinhos, Olímpia, Osvaldo Cruz, Palmeiras, Pradópolis, Penápolis, Pirajuí, Piracicaba, Piedade, Pindamonhangaba, Pindorama, Peruíbe, Parelheiros, Presidente Epitácio, Presidente Prudente, Presidente Bernardes, Presidente Venceslau, Rancharia, Ribeirão Pires, Rio Claro, Rincão, Santos, São Carlos, São Roque, São Sebastião, Santana de Parnaíba, Santa Isabel, Santa Rita do Passa Quatro, São Miguel Arcanjo, São João da Boa Vista, São José do Rio Preto, São João Novo, Suzano, Sertãozinho, Taciba, Tambaú, Taboão da Serra, Três Fronteiras, Tatuí, Tupã, Valparaíso, Votuporanga, Valinhos.

$\mathrm{Na}$ tabela I estão relacionados os gêneros de serpentes examinadas. Estas foram identificadas pelo pessoal pertencente à Seção de Herpetologia do Instituto Butantan.

Examinei sistematicamente as serpentes duas vezes por semana. Os exemplares foram observados vivos; os parasitados foram anestesiados e, em seguida, removidos os parasitas um a um com escarificador e fixados em álcool $70 \%$. 


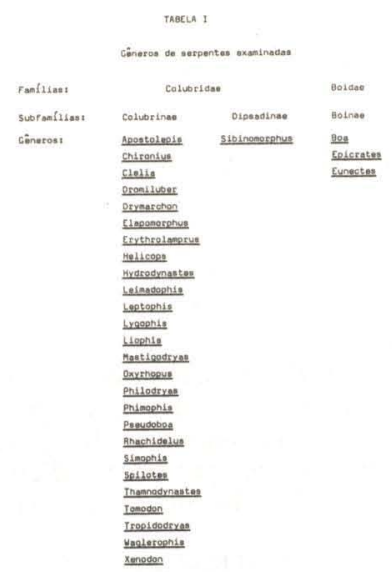

Com a finalidade de saber se houve influência da temperatura no parasitismo dividi este período de coleta em dois:

$$
\begin{aligned}
& \text { I - época de calor: outubro-março } \\
& \text { II - época de frio: abril-setembro }
\end{aligned}
$$

Os dados de temperatura e mapas climatológicos foram obtidos no Boletim Climatológico do Ministério da Agricultura.

Tendo em conta esta divisão, fiz o tabelamento dos dados (Tabela II).

$\mathrm{Na}$ Tabela III relacionei o total das espécies de serpentes examinadas e as parasitadas segundo as épocas do ano. $\mathrm{Na}$ tabela IV, os parasitas e seus hospedeiros.

\section{CONSIDERAÇOES GERAIS E SISTEMÁtiCAS}

1.1. Parasitas com alterância de gerações

Entre os parasitas com alterância de gerações foram encontradas duas famílias: Trombiculidae e Ixodidae, que podem parasitar tanto animais de sangue frio como de sangue quente (inclusive o homem).

\subsubsection{Família Ixodidae}

Gênero Amblyomma Kock, 1844

Bastante frequiente entre as serpentes em geral, está muito pouco representado nesta amostra; foi coletado em 4 gêneros de hospedeiros (Tabela IV), todos da subfamília Colubrinae, e aparece geralmente associado com Ixobioides (Família Ixodorhynchidae).

\subsubsection{Família Trombiculidae}

Os parasitas de serpentes desta família têm sido pouco estudados. Entretanto, estes ácaros encontram-se bastante difundidos entre as serpentes; coletei-os na maioria das espécies (Tabela IV) e, de modo geral, cada hospedeiro tem numerosos parasitas; $43 \%$ das serpentes estão parasitadas por trombiculídeos, quer isoladamente, quer em parasitismo múltiplo, especialmente associado com Ixobioides. Dois gêneros desta família parecem ser freqüentes: Fonsecia Radford, 1942 e Neotrombicula Hirst, 1915; é provável que haja gêneros novos.

\subsection{Parasitas exclusivos de serpentes}

Foram identificadas 2 famílias: Ophioptidae e Ixodorhynchidae, nas quais o parasitismo é típico em todas as fases de seu desenvolvimento. 
TABELK. II

Listegem des serpentes coletadas a das parasitadas nas duas épocas do ano: época de calor e época de frio

Apostalepis erythronota

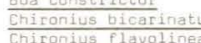

Chironius flavolineatus

Chironius laevilolis

fhironius quadricarinatu:

Clelía occipitolutea

Clelia plumbia

Drymanghor brazili

Elapomorphus merteris

picrates cenchria

Mythrolamprus aesculapii

Helicaps modesturs

Aydrodynastes bicinctus

Hydrodynastes gigas

eimadophis poecilogyrus

Keimadophis raginas

Leptophis ahaetulla

Liaphis undulatu

Lygophis meridionalis

Mastigodryas bifossatus

Oxyrnopus clathract

dxyshiopus trígeminus

philodryas olfersii

philodryas patagoniensis

semophis guerin

Phachidelus brazili

Slbinomorphus mikanit

Simophis rhinas toma

Thamnodynastas pallidus

Thamnodynastes strigatus

Tomodan dorsatus

Wapleroahis merremii

Xenadon neuwiedii

E: $n$ il de serpentes examinadas

tiv no serpentes parasitadas

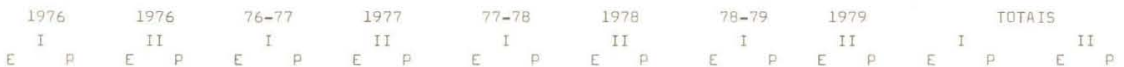




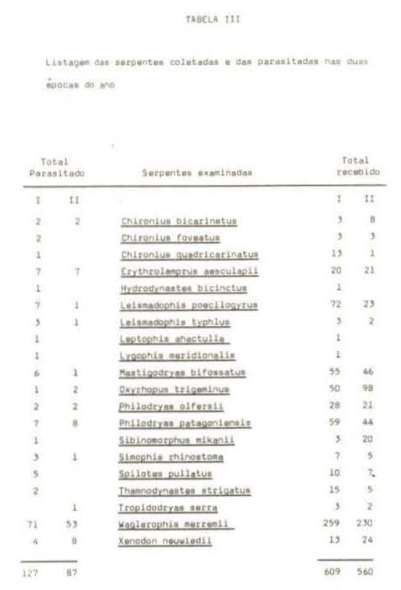

\subsubsection{Família Ophioptidae \\ Gênero Ophioptes Sambom, 1928}

Encontram-se geralmente alojados em orifícios ou crateras escavadas nas escamas das regiões laterais e dorsal do hospedeiro, habitualmente no terço anterior e médio do corpo, e foram encontrados repetidas vezes caminhando lentamente sobre as escamas.

Ophioptes Sambom compreende 11 espécies, das quais 2 são da Região Neotropical: Ophioptes parkeri Sambom parasita 4 gêneros de serpentes que ocorrem no Brasil, Bolívia, Paraguai e Argentina, e Ophioptes dromicus Allred, 1958, parasita o gênero Leimadophis Schleger, que ocorre em Cuba.

Encontrei este gênero parasitando 7 gêneros de serpentes, 5 dos quais não citados anteriormente (Tabela IV). 


\subsubsection{Família Ixodorhynchidae}

Os Ixodorhynchidae são ácaros ovíparos ou larvíparos; apresentam ampla distribuição geográfica, e foram coletados em todas as fases de seu desenvolvimento. Fain (1962) estudou especialmente material das Regiões Neártica e Etiópica.

$\mathrm{Na}$ Região Neotropical encontram-se 5 gêneros: Ixobioides Fonseca, 1934, Ixodorhynchus Ewing, 1923, Chironobius Lizaso, 1983, Ophiogongylus Lizaso, 1983 e Strandtibbettsia Fain, 1961, sendo este último citado também para a Ásia (uma espécie).

No material estudado encontrei os gêneros Ixobioides, Chironobius e Ophiogongylus.

Ixobioides Fonseca foi descrito como parasita de Waglerophis merremii (Wagler). É encontrado em grande quantidade sobre o hospedeiro, com bastante freqüência na cavidade ocular, na parte inferior da cabeça e de modo geral no terço anterior do corpo; no terço médio é mais escasso e é raro encontrá-lo no terço posterior (às vezes em serpentes com superparasitismo).

A espécie mais abundante é Ixobioides butantanensis Fonseca, 1934. Verifica-se grande variedade de tamanho nos exemplares adultos.

Ixobioides brachispinosus Lizaso, 1983, parece preferir como hospedeiro Xenodon neuwiedii (Gunther). Geralmente encontra-se localizado debaixo das escamas ventrais.

Ophiogongylus Lizaso, 1983 é coletado sempre debaixo das escamas ventrais, de modo geral no terço anterior do corpo da serpente e nunca no posterior. A espécie mais abundante, Ophiogongylus rotundus, parasita de Xenodon neuwiedii (Gunther), foi encontrada uma vez em Erytrolamprus aesculapii (Linneaus). Ophiogongylus breviscutum Lizaso, 1983 parece preferir como hospedeiro Leimadophis (Schleger).

Chironobius alvus Lizaso, 1983, parasita Chironius bicarinatus (Wied).

\section{CONSIDERAÇÖES ECOLOGICAS E RESULTADOS}

\subsection{Parasitismo múltiplo}

Verifiquei que $75 \%$ das serpentes são parasitadas por uma única espécie de ácaros, $21,6 \%$ por duas espécies e as restantes, 3,4\% por três espécies (Tabela V). Trombiculidae é a família mais freqüente no parasitismo múltiplo.

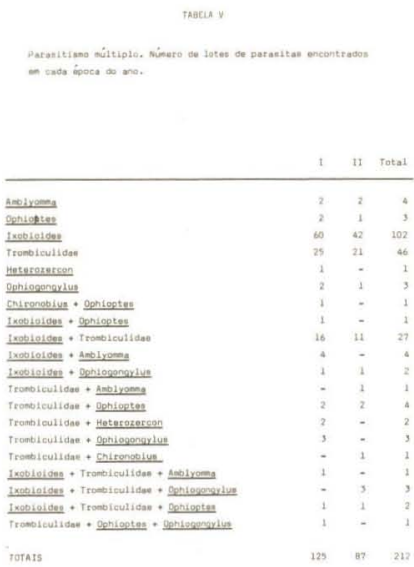




\subsection{Superparasitismo}

Observei-o em Waglerophis merremii (Wagler), parasitado especialmente por Ixobioides butantanesis Fonseca, e em Erythrolamprus aesculapii (Linnaeus) e Oxyrhopus trigeminus (Duméril, Bibon and Duméril) (falsas corais) parasitadas por Trombiculidae (na grande maioria localizados debaixo das escamas ventrais).

\subsection{Especificidade}

Se considerarmos especificidade como preferência do parasita por determinado hospedeiro, tudo parece indicar que não há muita especificidade entre os ácaros de serpentes.

Pude constatar que Ophiogongylus breviscutum parece parasitar exclusivamente Leimadophis Schleger; Ophiogongylus rotundus parece preferir Xenodon Gunther, apesar de ter sido coletado também em um exemplar de Erythrolamprus Linnaeus.

\subsection{Diversidade da fauna acarológica}

Segundo a tabela IV há diferenças entre os gêneros de serpentes em relação à quantidade de espéciẹs de ácaros que as parasitam. Assim, Wagle'rophis merremii (Wagler) e Erythrolamprus aesculapii (Linnaeus) são parasitados pela maioria das espécies de ácaros coletados, enquanto que outras serpentes se apresentam parasitadas por uma só espécie de ácaros. Este dado deve ser confirmado por outras coletas, já que no material estudado o número 'de exemplares examinados é pequeno.

Considerando o hábitat das serpentes estudadas, Hydrodynastes Fitzinger é semi-aquática e estava parasitada por Amblyomma; as restantes serpentes examinadas são de hábitat terrestre ou arborícola e não apresentam diferenças em relação às espécies de ácaros pelas quais são parasitadas.

\subsection{Indice de parasitismo}

Se considerarmos as espécies de serpentes que se encontravam parasitadas, em cada uma das épocas do ano estabelecidas, a porcentagem é pouco significante quando comparada com o total das serpentes coletadas (Tabelas VI e VII) sendo sempre maior a porcentagem de parasitose na época I.

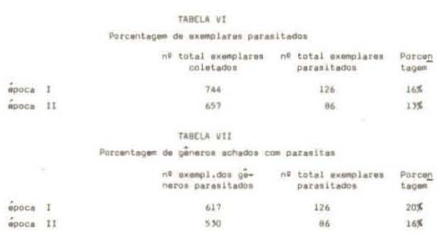

Para algumas espécies de serpentes o índice de parasitismo é de valor inverso ao índice geral, isto é, é maior a porcentagem de parasitismo na época II. Isto verifica-se em:

Philodryas patagoniensis: época I $11 \%$

Xenodon neuwiedii: época I $30 \%$

época II $33 \%$ 
2.6. Abundância de cada gênero de ácaros

O gênero Ixobioides aparece parasitando grande número de serpentes (Tabela VIII), quer se considere como parasita único de um hospedeiro, quer se considere múltiplo. Foi coletado em $66,5 \%$ das serpentes parasitadas. Os Trombiculidae parasitam $42,4 \%$ das serpentes; na maioria dos casos se apresentam como parasitas exclusivos de um hospedeiro.

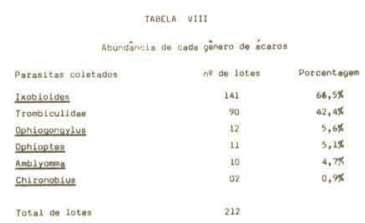

\subsection{Influência da temperatura}

As variações de temperaturas médias das duas épocas do ano pré-estabelecidas é relativamente pequena e portanto não se pode inferir que exista uma influência reguladora ou limitante, embora na "época de calor" o índice de parasitismo apresente uma pequena elevação.

REFERENCIAS

Fain, A., 1962. Les acariens mesostigmatiques ectoparasites des serpents. Bulln Inst. r. Sci. nat. Belg. 38: 1-149.

Lizaso. N. M., 1983. Ácaros ectoparasitas de serpentes. Descrição de novos gêneros e espécies (Mesostigmata, Ixodorhynchidae). Revta bras. Zool. 1(3): 193.201 . 